\title{
Do racismo epistêmico às cotas raciais: A demanda por abertura na universidade
}

\author{
From epistemic racism to racial quotas: \\ The demand for university openness
}

\section{Zilda Martins}

Pós-doutoranda em Comunicação e Antropologia do Contemporâneo pela École des Hautes Études en Sciences Sociales (EHESS), Doutora em Comunicação e Cultura pela Escola de Comunicação da UFRJ, pesquisadora do Laboratório de estudos em Comunicação Comunitária (LECC/UFRJ) e coordenadora do Grupo de Estudos sobre Relações Raciais no Brasil. Bolsista Capes.

Email: zildamarti@yahoo.com.br

\section{Raika Julie}

Mestra em Comunicação e Cultura pela Escola de Comunicação da UFRJ e integrante do Grupo de Estudos sobre Relações Raciais no Brasil.

Email: raika.moises@gmail.com

\section{Angélica Basthi}

Mestra em Comunicação e Cultura pela Escola de Comunicação da UFRJ, com bolsa do Programa Internacional de Bolsas de Pós-Graduação da Fundação Ford, e integrante do Grupo de Estudos sobre Relações Raciais no Brasil.

Email: angelicabasthi@uol.com.br

\section{Amanda Moura}

Jornalista e integrante do Grupo de Estudos sobre Relações Raciais no Brasil.

Email: amanda.moura87@gmail.com

\section{Lídia Michelle Azevedo}

Jornalista e integrante do Grupo de Estudos sobre Relações Raciais no Brasil.

Email: lidiamichelle@gmail.com 


\section{RESUMO}

Este artigo é uma reflexão acerca do racismo, a partir do diálogo entre intelectuais negros e negras, professores e pesquisadores de diferentes campos do saber de universidades brasileiras. Os entrevistados apontam o contraste entre o racismo epistêmico, eurocentrado, e a nova realidade dos campi diante das políticas públicas de ações afirmativas e cotas raciais. Ressaltam o tensionamento da questão e a demanda de abertura para o pensamento crítico sobre a nova realidade das relações raciais brasileiras, que exigem transformação. Fenômenos comunicacionais também são debatidos, assim como a necessidade de um novo ethos social, livre da herança da opressão colonial.

PALAVRAS-CHAVE: Racismo; Racismo epistêmico; Intelectuais negros, Universidade; Comunicação

\section{ABSTRACT}

This article highlights about racism throughout a debate made by black intellectuals, professors, and researchers of different fields from Brazilian universities. The interviewers point out the contrast between epistemic racism, eurocentric, and the new reality of the campuses throughout public policies of affirmative actions and quotas. They also emphasize the tension about this issue, and the need for openness to critical thinking about the new reality of Brazilian race relations, which demand transformation. Communicational phenomena are also debated as well as the need for a new social ethos, free from the heritage of colonial oppression.

KEYWORDS: Racism; Epistemic Racism; Black Intellectuals; University; Communication;

\section{RÉSUMÉ}

Cet article est une réflexion au sujet du racisme, a partir des dialogues entre les intellectuels noir.e.s, professeurs et chercheurs de différents domaines du savoir des universités brésiliennes. Les sondés attirent l'attention par le contrast entre le racisme épistémique, eurocentrique, et la nouvelle réalitée des campus dévant des politiques publiques des actions affirmatives et quotes raciales. Ils soulignent les tensions de la question et la demande d'ouverture pour la pensée critique au sujet de la nouvelle réalitée des rapports raciales brésiliennes, qui demandent profonde modification. Des phénomènes communicacionelles sont aussi en débat, bien que la nécessitée d'un nouvel ethos social, libre des héritages d'oppression coloniale.

MOTS-CLÉS: Racisme; Racisme Épistémique; Intellectuels Noirs; Universités; Communication.

\section{Introdução}

Racismo não é coisa de ignorante. É coisa de profissional que usa desta prática para negar direitos básicos que ele entende

Dossiê Racismo - revistas.ufrj.br/index.php/eco pos - ISSN 2175-8689 - v. 21, n. 3, 2018.

DOI: 10.29146/eco-pos.v21i3.20276 
como privilégio. Racismo é coisa de profissional, é estruturante para o exercício de poder contra quem o racista julga ser inferior. Não se enganem, o racista tem plena consciência do seu ato. - Sueli Carneiro

Quantas pessoas negras têm a oportunidade de subverter a lógica do imaginário coletivo dominante, alcançando autonomia desse imaginário para si e suas histórias, quando o que se apresenta, grosso modo, é de que o belo, o bom gosto, está justamente no que se vê fora do espelho? Frantz Fanon exemplifica a situação ao afirmar que:

O mundo branco, o único honesto, rejeitava minha participação. De um homem exige-se uma conduta de homem; de mim, uma conduta de homem negro - ou pelo menos uma conduta de preto. Eu acenava para o mundo e o mundo amputava meu entusiasmo. Exigiam que eu me confinasse, que encolhesse (FANON, 2008, p. 107).

O que o mundo apresentado por Fanon e o mundo atual definem (e ditam) como "conduta de preto" é justamente esse lugar menor, menosprezado, desqualificado, sem ou quase sem qualidades e repleto de erros. 0 sujeito negro ao ser silenciado repetidas vezes vai se tornando mudo, imperceptível, tendo como destino final - consentido - o extermínio ou morte desassistida, sem causar desconforto para quem o ignora.

Ancorado em debates estabelecidos nos últimos três anos, no âmbito do Grupo de Estudos sobre Relações Raciais no Brasil1 ${ }^{1}$, este artigo inicia uma reflexão sobre o mal-estar civilizatório provocado pelo corpo negro em um espaço tradicional de poder, a universidade pública, lugar de produção de conhecimento, colocando em questão sua dificuldade de se abrir para a diversidade. Apresenta as visões de intelectuais negros de diferentes campos do saber sobre o racismo em instituições públicas de ensino superior que adotam ações afirmativas para estudantes negras/os, e como eles e elas lidam com esse problema. O objetivo é expor as narrativas sobre a temática, a partir do olhar de profissionais negras/os que atuam como professoras/es em universidades públicas brasileiras.

Historicamente, a prática acadêmica evidencia o apagamento de biografias de intelectuais negras/os, o esvaziamento de singularidades por narrativas descontextualizadas e

\footnotetext{
${ }^{1}$ Grupo criado em 2015, na Escola de Comunicação da Universidade Federal do Rio de Janeiro (ECO/UFRJ), como parte das atividades de ensino, pesquisa e extensão do Laboratório de Estudos em Comunicação Comunitária (LECC).
}

Dossiê Racismo - revistas.ufrj.br/index.php/eco pos - ISSN 2175-8689 - v. 21, n. 3, 2018. 
distanciadas da história, e isto é uma estratégia discursiva poderosa que resulta em danos irreparáveis na vida de pessoas negras. Sueli Carneiro (2003) afirma que uma das características principais do racismo é a maneira pela qual ele aprisiona o outro em imagens fixas e estereotipadas, enquanto reserva aos racialmente hegemônicos o privilégio de serem representados em sua diversidade. Nos meios convencionais de comunicação, é ação rotineira exibir comercial, de forma isolada, por exemplo, em que um negro aparece na multidão de brancos para assegurar suposto respeito e valorização da diversidade étnica e racial e livrar-se de possíveis acusações de exclusão racial das minorias (CARNEIRO, 2003). A população negra sempre esteve à margem da sociedade brasileira, cuja política de construção da cultura nacional estruturou as relações sociais ancoradas no poder branco. A negritude ${ }^{2}$ padece de toda sorte de indagações (Idem, 2003), inclusive da existência de um sujeito verdadeiramente humano.

Na teoria cultural contemporânea, é justamente no interior dos sistemas de representação que identidade e diferença ganham sentido. "É por meio da representação que, por assim dizer, a identidade e a diferença passam a existir. Representar significa nesse caso, dizer: 'essa é a identidade', 'a identidade é isso'” (SILVA, 2000). Hall dirá que

toda identidade tem, à sua margem, um excesso, algo a mais. A unidade, a homogeneidade interna, que o termo 'identidade' assume como fundacional não é uma forma natural, mas uma forma construída de fechamento: toda identidade tem necessidade daquilo que lhe 'falta' mesmo que esse outro que lhe falta seja um outro silenciado e inarticulado. Laclau (1990) argumenta de forma persuasiva, que a 'constituição de uma identidade social é um ato de poder', 'pois se uma identidade consegue se firmar é apenas por meio da repressão daquilo que a ameaça (HALL, 2000, p.100).

Para Tomaz Tadeu da Silva, "a representação é como qualquer sistema de significação, uma forma de atribuição de sentido" (SILVA, 2000, p. 91). Como tal "é um sistema linguístico e cultural: arbitrário, indeterminado e estreitamente ligado a relações de poder." (Idem, ibidem, p. 91). Ou seja, quem possui mais poder de representar possui também mais poder de definir identidades. A comunicação hegemônica encarrega-se do silenciamento do afrodescendente,

\footnotetext{
2 Compreendemos a Negritude a partir do conceito de Aimé Césaire (2010), de consciência racial e ação política. Contudo, no texto acima é usado em contraposição à branquitude.
} 
reforçando o poder instituído. Como a mídia não apenas nomeia o mundo, mas o institui (SODRÉ, 2002), cria realidade, cujo conteúdo real e simbólico reflete no cotidiano.

Neste trabalho a orientação é iniciar um debate sobre o racismo estrutural que insiste em desumanizar, anular a subjetividade e as condições de possibilidade de mobilidade social, em contradição com a luta por direitos civis, como as ações afirmativas. 0 que se pretende é compreender fenômenos sociais e midiáticos em sua multidimensionalidade, recortando-os a partir do pensamento de intelectuais dos campos da educação, filosofia, comunicação, antropologia, e que podem traduzir uma conjuntura política, cultural e histórica mais ampla.

\section{A incontornável construção do racismo}

A raça e o racismo são construções sociais (MOORE, 2010), assim como o negro é uma invenção do colonialismo (MBEMBE, 2017) para fins de exploração. Os horrores cometidos pela colonização triangular - Europa, África e Américas - no processo de dominação dos povos africanos, são fortemente denunciados por Césaire em verso e prosa. Para o autor, tal processo resultou em uma desconstrução civilizatória, violenta desqualificação, inferiorização e desumanização, cujo combate demanda atitude política a partir da Negritude.

A Negritude resulta de uma atitude proativa e combativa do espírito. Ela é um despertar; despertar de dignidade. Ela é uma rejeição; rejeição da opressão. Ela é luta, isto é, luta contra a desigualdade. Ela é também revolta. [...] revolta contra aquilo que eu chamaria de reducionismo europeu. (CÉSAIRE, 2010, p. 109-110).

Podemos questionar qual a relação da escrita do jovem martinicano com a realidade brasileira. Com efeito, essa relação existe porque o Brasil é um país que importou, como mercadorias, deportando de seus territórios, cerca de cinco milhões de seres humanos para fins de cativeiro, foi o último a abolir a escravidão e ainda mantém na contemporaneidade uma sociedade profundamente racista, de mentalidade escravocrata.

Logo, a defesa de Césaire continua vibrante nos dias presentes, sobretudo quando o intelectual afirma, em seu Discurso sobre o colonialismo (1985): "uma civilização que se revela incapaz de resolver os problemas que o seu funcionamento suscita, é uma civilização decadente. Uma civilização que prefere fechar os olhos aos seus problemas mais cruciais é uma civilização enferma." (CÉSAIRE, 1985, p. 13). O autor refere-se à Europa com sua civilização 
ocidental que, segundo ele, é incapaz de resolver os dois maiores problemas societários, construídos naquele continente: "o problema do proletariado e o problema colonial" (Idem, ibidem, p. 13). Ainda que ambos tenham origem no continente europeu, afetam outras culturas e potencializam a atualidade da afirmação do poeta: "Uma civilização que trapaceia com os seus princípios, é uma civilização moribunda" (Idem, ibidem, p. 13).

Considerando as relações raciais no Brasil e a herança da escravidão silenciada social e midiaticamente, afirmamos com Césaire (1985) e com Fanon (2008) que vivemos em uma "sociedade patológica”. Não faltam exemplos de relações raciais impregnadas de racismo, o que evidencia a enfermidade social. Em março de 2018 um estudante de administração da Fundação Getúlio Vargas (FGV-SP) se viu envolvido em um episódio de racismo por um colega que fazia menção à escravidão, reatualizando a ideia da maior atrocidade histórica cometida contra o ser humano. 0 rapaz branco compartilhou uma foto do colega negro em rede social seguida de legenda "Encontrei esse escravo aqui no fumódromo. Quem for o dono avisa." 0 fato, chocante e criminoso, repercutiu nos jornais e a FGV suspendeu o racista por 90 dias. Fosse um caso isolado, já seria suficiente para se repensar o ethos da sociedade brasileira.

Constituída sob a égide do patrimonialismo e da oligarquia, como observa Sodré (2015), a sociedade brasileira herdou dos portugueses as relações de poder baseadas no modelo europeu colonial de dominação, subalternização e racismo. “Geralmente, ao falar-se de racismo, está-se fazendo referência à segregação dos indivíduos por raça (racismo de dominação) ou então ao racialismo (pressuposto de raças, com diferentes aptidões sociais), que redunda no racismo de exclusão." (SODRÉ, 2015, pp. 91-92). O autor explica que “a exclusão da diferença como constitutiva da própria identidade é o pressuposto de todo racismo, do mais grosseiro ao mais sutil, que advoga a exclusão da diferença como respeito da singularidade" (Idem, ibidem, p. 92).

Moore acrescenta que "a Modernidade deu lugar às grandes reflexões sobre Cultura e Identidade que continuam a dominar os debates sobre as sociedades" (2010, p. 8). 0 autor refere-se aos argumentos teóricos e científicos que surgiram a partir do século XVI, a fim de legitimar a política de dominação contra os povos africanos e a segmentar a superioridade dos Europeus. Explica que a raça seria delimitada oficialmente, a partir da geografia, da civilização e da própria raça, resultando na Europa "branca", na Ásia "amarela" e na África "negra", consolidando a noção de raça. E acrescenta que "a raça e o racismo foram erigidos pelos não 
negros em uma metaconsciência totalizadora, definidora do humano em termos puramente tautológicos, maniqueístas e essencialistas, como fruto de uma metavisão hegemônica" (MOORE, 2010, p. 9).

Outra manifestação de racismo ocorreu no Rio de Janeiro, durante os Jogos Jurídicos Estaduais anuais de 2018, em Petrópolis, em que atletas de diversas faculdades de Direito competiam. 0 incidente envolveu torcedores da Pontifícia Universidade Católica do Rio de Janeiro (PUC-Rio), contra estudantes da Universidade do Estado do Rio de Janeiro (UERJ), da Universidade Federal Fluminense (UFF) e da Universidade Católica de Petrópolis (UCP). De acordo com relatos dos jornais e redes sociais, atletas negros e torcedores foram ofendidos, chamados de macacos e cascas de bananas foram arremessadas contra eles.

A violência do racismo não é praticada apenas por alunos contra seus colegas. Em fins de 2014, um professor da Universidade Federal do Espírito Santo disse em sala de aula que não se consultaria com profissionais negros, como médicos ou advogados. Sem constrangimento, criticou as políticas públicas de ações afirmativas, alegando que alunos negros, por serem pobres, não eram preparados culturalmente, não eram socializados adequadamente e eram, portanto, despreparados para o mercado de trabalho. A denúncia também repercutiu em jornais e o professor foi demitido em novembro de 2015. Contudo, já em março do ano seguinte teria sido readmitido por decisão judicial, em uma medida que tipifica a "civilização moribunda", apresentada por Césaire (1985, p. 13).

Acusar profissionais negros/as de despreparados/as para o mercado de trabalho é insistir numa mentalidade colonialista em que "poder e identidade" atuam juntos, como afirma Djamila Ribeiro (2017), na tentativa - de acordo com o contexto - de construir, legitimar ou deslegitimar certas identidades. É o caso do tal professor racista, assim como daqueles que qualificam intelectuais negros/as de “aficionados por políticas identitárias” (RIBEIRO, 2017, p. 31), a fim de confundir "aquilo que se deseja provar, pois o objetivo principal ao confrontarmos a norma, não é meramente falar de identidades, mas desvelar o uso que as instituições fazem das identidades para oprimir ou privilegiar" (RIBEIRO, 2017, p. 31). O modelo eurocêntrico, defendido pelo professor racista, reforça a importância de debater-se a existência das minorias.

Como intelectuais negras/os narram a existência do racismo em seu próprio campo de trabalho, as universidades públicas federais ou estaduais? Essa é a questão discutida nesse artigo. Para a professora e pesquisadora da Universidade Federal do Estado do Rio de Janeiro 
(Unirio), Cláudia Miranda (2018), o racismo ancora-se numa estrutura de opressão, que contamina e alimenta todo um sistema sociocultural. "Nada escapa dessa lógica [...]. Na universidade, o racismo também é implacável," declara. A educadora define o racismo, como imposição colonial de dominação:

O caráter histórico do racismo tem a ver com o conceito de "colonialidade do poder", do sociólogo peruano Aníbal Quijano, em que ele busca refletir sobre o discurso da existência de raça relacionado à empreitada dos países, majoritariamente europeus, que conseguiram recursos materiais e bélicos para dominar outros grupos do mundo. 0 racismo faz parte desse processo de subalternização do outro e que estrutura as sociedades pelas hierarquias e nos diferencia pela raça. (MIRANDA, 2018).

No campo da Comunicação, a professora e pesquisadora da Universidade Federal de Goiás, Luciene Dias, denuncia. "No ambiente acadêmico, o racismo tem essas características gerais, mas assume certas especificidades. E essas especificidades tornam o combate a ele ainda mais complicado neste espaço" (DIAS, 2018). Ora, sendo a universidade um espaço público por excelência, lugar legitimado de fala, de produção do conhecimento e de busca de transformação, haveria de se supor a inexistência do racismo, ou o seu combate. Ao invés de reprodução do racismo, não seria mais coerente a universidade ser um oásis do pensamento contra a opressão e espaço de contestação? Ao contrário, os protagonistas da academia se recusam a se assumirem como racistas. "Esta negação do racismo torna o combate de quem o vivencia muito difícil, porque o tempo todo o outro lado busca argumentos que negam o seu racismo" (Idem).

Refletindo sobre a universidade no mundo contemporâneo, Derrida afirma que

A universidade deveria [...] ser também o lugar em que nada está livre do questionamento, nem mesmo a figura atual e determinada da democracia, nem mesmo a ideia tradicional de crítica, como crítica teórica, nem mesmo ainda a autoridade da forma "questão", do pensamento como "questionamento". (DERRIDA, 2003, p. 18).

O autor ainda desvenda a autonomia universitária, do ponto de vista do "poder" e da sua própria existência, apresentando incoerências e propondo a desconstrução do modelo atual para um novo devir ou o que chama de "universidade sem condição", explicada como o "direito de princípio de dizer tudo, ainda que a título de ficção e de experimentação do saber, e o direito 
de dizê-lo publicamente, de publicá-lo" (Idem, ibidem, p.18). Nesse contexto de autocrítica na esfera pública, o debate acerca do racismo na academia deveria ser plenamente praticado entre os corpos docentes e discentes, contudo, de acordo com as/os intelectuais negras/os entrevistadas/os, isso não acontece.

“Não existe debate a respeito [do racismo] entre os/as professores/as." A afirmação é da antropóloga Maria Alice Rezende, professora da UERJ. Ora, se nem mesmo na Universidade do Estado do Rio de Janeiro, pioneira na abertura para a diversidade, o tema é encarado, há um descompasso entre o anseio por uma universidade plural, "pluriétnica e pluricultural" (REZENDE, 2018) e a realidade. Esta nos leva a constatar o racismo como fenômeno social, que "se manifesta no campo profissional por meio de diversas estratégias de hierarquização. Como o racismo é crime, a universidade inibe as ações racistas, no entanto, identificamos a prática no cotidiano da instituição" (Idem).

Tal realidade também é apontada pelo professor e pesquisador da UERJ, Nemézio Amaral Filho, ao afirmar que "o racismo atravessa todo o tecido social" (AMARAL FILHO, 2018). 0 intelectual acrescenta que "professores negros são raros na Universidade do Estado do Rio de Janeiro. Se numa universidade inclusiva a realidade é essa, o que podemos esperar de outras instituições de ensino superior? Isso diz muito sobre o país que somos e aquilo que toleramos" (Idem). No entanto, ainda que timidamente, ambas, realidade e desejo, começam a se aliar.

Tenho orgulho de trabalhar numa universidade inclusiva, a resistente UERJ, a primeira no Estado do Rio de Janeiro a adotar o sistema de cotas. Aliás, segundo relatório da Comissão de Avaliação da Lei de Cotas, em documento datado de 24 de outubro de 2017, a experiência da UERJ é um sucesso e me pergunto porque não é replicada mais celeremente país afora. (AMARAL FILHO, 2018).

Evidentemente que a mídia dominante não tem interesse em divulgar o sucesso das ações afirmativas, considerando que sua própria narrativa maniqueísta do início da implantação das políticas públicas apontava para um prognóstico ameaçador de "guerra das raças".

A professora e pesquisadora da UERJ, Rosangela Malachias, observa que "o racismo se manifesta na sociedade e como tal o espaço de trabalho não deixa de ser o corpo dessa sociedade" (MALACHIAS, 2018). Para a pesquisadora, "não é possível compreender a sociedade 
brasileira sem compreender que o racismo é estrutural" (Idem). Lembra que "um autor que fala disso com propriedade é o historiador Clóvis Moura; e pensar no racismo institucionalizado, compreendendo como institucionalização a ação política dos governos e dos seus órgãos na perpetuação das desigualdades" (Idem). No campo da comunicação, a entrevistada salienta que nessa área:

o racismo é explícito pela própria invisibilidade da população negra nas mídias, não apenas como protagonistas, como aqueles que estão nos bastidores, atrás das câmeras, na produção e também na redação de histórias e roteiros. Ainda temos poucos profissionais negros no campo da comunicação contratados e trabalhando nas grandes empresas (MALACHIAS, 2018).

O consenso quanto ao racismo enquanto fenômeno social alia a universidade à sociedade, tornando solitário o trabalho no campo acadêmico. Na rua ou na universidade há um deslocamento no que se refere ao pertencimento. “O racismo se manifesta no meu campo profissional diretamente, no primeiro momento, no seu conteúdo, porque a gente está aí dentro de um espaço onde a nossa epistemologia é absolutamente branca" (FELISBERTO, 2018). De acordo com a professora da área de Educação da Universidade Federal Rural do Rio de Janeiro (UFRRJ), Fernanda Felisberto, sempre é "imposto que temos que nos adaptar, entrar numa roupa mais curta que o nosso corpo" (Idem, 2018). A pesquisadora acrescenta que a grade de conteúdos não representa a pluralidade de pensamentos. Além disso, a intelectual explica que nas relações construídas com os alunos, principalmente com os alunos negros, há também algo fora do lugar. "Eles nos tiram do lugar de professor e pensam que somos colegas. [...] Ao mesmo tempo que reclamam da falta de atenção que o professor branco, na vez do professor negro tudo tem de ser relevado." (FELISBERTO, 2018).

$\mathrm{Na}$ área de Filosofia, a professora e pesquisadora Katiúscia Ribeiro, da Universidade Federal do Rio de Janeiro (UFRJ), entende o racismo epistêmico como uma realidade concreta, que lida com as epistemologias de forma universal direcionadas sempre ao Ocidente, negando qualquer outra possibilidade de reflexão do sujeito fora dessa perspectiva. 0 racismo atua nessa esfera como a negação do próprio pensamento. A intelectual menciona Theophile Obenga para ressaltar: "a Filosofia nasceu em tempos imemoráveis, como nos sinaliza o filósofo. Onde há pensamento humano, existe filosofia” (RIBEIRO, 2018). Ainda assim, observa que apenas aqueles que tiveram a humanidade garantida - os brancos - têm o pensamento 
reconhecido. "Essa é a dimensão do racismo existente nos cânones filosóficos que impede os diálogos africanos em suas realidades epistêmicas. É a manifestação concreta da negação das filosofias e apagamento racial de nossas intelectualidades" (Idem).

\section{Racismo na universidade: eurocentrismo x novas demandas}

“O racismo se manifesta na sociedade, logo, estará presente também nos espaços de trabalho, que não deixam de ser corpos dessa sociedade" (MALACHIAS, 2018). Neste contexto está inserida a universidade, que cumpre seu papel na manutenção da política excludente da sociedade brasileira. Não só por não estar imune a essa desigualdade, mas porque é no espaço acadêmico que acontece uma parte importante da construção de subjetividades que consolidam o racismo estrutural no qual vivemos.

Essa análise é corroborada por Silvio Almeida na obra $O$ que é racismo estrutural?, quando o autor afirma que o "racismo constitui todo um complexo imaginário social que a todo momento é reforçado pelos meios de comunicação, pela indústria e pelo sistema educacional." (ALMEIDA, 2018, p. 51). A academia, lugar de produção de saberes, toma para si o direito de dizer o que e quem deve ser lido, que história deve ser contada, como e por quem. Logo, a academia é um reflexo da sociedade misturada a uma ausência de autocrítica.

Por mais que gostemos de pensar que a universidade é uma ilha de tolerância e reflexão "pura", a verdade é que essa instituição também é um reflexo do pensamento de nossa sociedade extremamente conservadora. o que quero dizer é que não haverá uma discussão sobre o racismo, ou qualquer outro grande tema da representação social, enquanto a universidade não discutir a si mesma. Aí volta a questão do contexto social. A instituição tem uma enorme dificuldade em se comunicar com quem a financia - o povo - ao mesmo tempo em que parece se sentir segura, em muitos sentidos, atrás de seus muros de marfim. (AMARAL FILHO, 2018).

As análises feitas pelos entrevistados dialogam entre si, em consenso, no sentimento de que a universidade só se tornará institucionalmente plural quando as ações em prol da diversidade forem para além do fazer cumprir as políticas de ações afirmativas determinadas por lei. Segundo os intelectuais, ao invés de a academia tratar as relações raciais como um objeto de estudo formal e distante da realidade vivida pela instituição, deveria discutir a 
questão racial de maneira profunda, porque "a ciência tem o poder de produzir um discurso de autoridade que poucas pessoas têm a condição de contestar, salvo aquelas inseridas nas instituições em que a ciência é produzida" (ALMEIDA, 2018, p.54).

Silvio Almeida retoma o antropólogo Kabengele Munanga para dizer que o “'preconceito' não é um problema de ignorância, mas de algo que tem sua racionalidade embutida na própria ideologia" (2018, p. 55), tanto que esteve presente na construção do nazismo e no regime do apartheid, por exemplo. A pesquisadora Luciene Dias reforça a ausência do debate num âmbito mais amplo

[...] pela minha experiência pessoal há, sim, uma abertura para a discussão sobre o racismo, mas esta abertura está concentrada nos corpos negros. Não noto nos corpos brancos uma abertura real de combate ao racismo, percebo que muitos enxergam o racismo como um bom objeto de pesquisa apenas. Vemos, neste cenário, brancos pesquisando negros apenas para valorizarem os seus próprios currículos, em meio a poucos bem-intencionados. Este oportunismo não é específico das pesquisas sobre relações étnico-raciais, faz parte da compreensão de ciência, em que determinados grupos humanos se transformam em objetos de pesquisa (DIAS, 2018).

Para Dias, os debates mais profundos sobre a questão da raça são protagonizados por acadêmicos negros; a universidade ainda não está aberta à novas reflexões, nem a novas ações. A intelectual defende o encontro de todo o corpo docente e discente - formado por cotistas e não cotistas - a fim de reconhecer a existência de novas epistemologias, que possam ou não dialogar com a bibliografia eurocêntrica aplicada atualmente, abrindo espaço para novos saberes que ajudem a construir novos atores sociais.

"Sofremos com o racismo epistêmico", afirma Ribeiro, ao observar que as referências sempre foram apresentadas a partir do olhar ocidental, predominante nos espaços acadêmicos. "Fixar as bibliografias a partir desta realidade vigente nas universidades não abre precedente para conhecer outras bibliografias importantes para os currículos educacionais" (RIBEIRO, 2018). Na opinião da pesquisadora,

é preciso com urgência eliminar o epistemicídio e o apagamento epistêmico das bibliografias africanas. Mas, primeiro, a universidade precisa reconhecer as realidades de cunho racial existentes nela mesma. A academia é branca e elitista e precisa se reconfigurar e compreender que a entrada de cotas e de estudantes pretos nas graduações e pós-graduações 
trouxeram outra realidade. 0 racismo passou a ser um dos temas mais pesquisados e desenvolvidos, assim como as epistemologias decoloniais. As universidades precisam se responsabilizar com as questões étnicasraciais e como elas incidem dentro da própria unidade (RIBEIRO, 2018).

É evidente, assim, que a construção de um currículo pedagógico plural e diverso passa, invariavelmente, por um corpo docente também plural e diverso. Por isso, é preciso que a administração da universidade trabalhe para que seus processos seletivos ocorram de maneira a garantir diversidade racial em seus quadros, "uma vez que a desigualdade educacional está relacionada com a desigualdade racial, mesmo nos sistemas de ensino público e universalizados" (ALMEIDA, 2018, p. 63).

Apenas desta forma os candidatos não se sentirão impelidos a aderir a determinadas políticas, discursos e posturas para serem aceitos por uma possível comissão de averiguação (MIRANDA, 2018), que na maioria dos casos trabalha para a manutenção da produção acadêmica eurocêntrica e "reafirma o imaginário que, em geral, associa competência e mérito a condições como branquitude, masculinidade e heterossexualidade e cisnormatividade" (ALMEIDA, 2018, p. 63).

Malachias lembra que, nos anos de 1960, o ativista e escritor norte-americano, Stokely Carmichael lutava pelos direitos civis dos afro-americanos e definia o racismo institucional como uma falha dentro do Estado. "Essa falha faz com que o Estado fique impedido de atingir todas as pessoas. Mas é uma falha programada para acontecer. Muitas vezes ela ocorre por conta do indivíduo que tem o poder de assinar alguma coisa" (MALACHIAS, 2018). Nesse sentido,

o documento defiro ou indefiro, nas mãos de um indivíduo, tem o poder de barrar institucionalmente o acesso de muitas pessoas. Este tipo de ação muitas vezes acontece por conta de um ou dois indivíduos, que acabam conseguindo inviabilizar a promoção da igualdade. Porém o que pesa não é a ação do indivíduo, mas o silêncio da instituição, que falha em aferir o que realmente aconteceu ou em verificar em seus quadros o porquê de não haver diversidade. (MALACHIAS, 2018).

A despeito das dificuldades, Dias destaca que tem sido possível abrir caminhos para novos diálogos. Conforme a pesquisadora, esse movimento acontece, prioritariamente, a partir de professores negros e das demandas dos alunos cotistas, já que alguns acadêmicos ainda 
"não aceitam a diversidade que transita pela universidade" (DIAS, 2018). De todo modo, a pesquisadora reconhece a preocupação de seus pares em tornar as bibliografias plurais, observando que há certa autonomia na escolha dos referenciais, portanto, na possibilidade de diversificação.

\begin{abstract}
Nas minhas disciplinas, por exemplo, há referências teóricas diversificadas e isso vai reconfigurando aos poucos a faculdade. Institucionalmente, não há essa exigência de que haja uma diversidade na bibliografia, mas é uma preocupação que deveria pautar as nossas discussões quando elaboramos as nossas disciplinas. Nossas ações sociais são agenciadas por nós e a partir delas as transformações vão acontecendo. Porém, às vezes nos falta força e apoio institucional, por isso, acho que seria interessante termos regulamentos específicos para que este processo seja agilizado (DIAS, 2018).
\end{abstract}

Djamila Ribeiro explica a subalternização intelectual, evidenciada e perpetuada pela não exigência institucional de uma bibliografia que contemple a diversidade. Isso ainda acontece porque os autores e autoras dessa bibliografia ainda são tratados socialmente de forma hierarquizada, mantidos "num lugar silenciado estruturalmente" (RIBEIRO, 2017, p. 63). Sem o apoio institucional, cabe aos acadêmicos que conseguem entrar no sistema de educação superior reivindicar não só o seu, mas o lugar de fala de toda a intelectualidade negra, tendo em mente que "o falar não se restringe ao ato de emitir palavras, mas de poder existir. Pensamos lugar de fala como refutar a historiografia tradicional e a hierarquização de saberes consequente da hierarquia social" (Idem, ibidem, p. 64). Neste sentido, "quando falamos de direito à existência digna, à voz, estamos falando de locus social, de como esse lugar imposto dificulta a possibilidade de transcendência. Absolutamente não tem a ver com uma visão essencialista de que somente o negro pode falar sobre racismo" (Idem, ibidem, p. 64).

Fernanda Felisberto anuncia como incluir uma bibliografia plural à ementa da disciplina que leciona em Literatura Brasileira do Século XIX, sobre José de Alencar: "passo por esse autor, mas incluo os autores negros que José de Alencar não abrange” (FELISBERTO, 2018). A preocupação em inserir novas epistemologias é comum entre os entrevistados.

Tento pensar a bibliografia tanto na perspectiva de clássicos e de professores brancos, que já passaram por aquele tema, como também trazer referências de autores e autoras negras que falam do mesmo tema, com uma abordagem diferenciada. Isso é fundamental. Um exemplo é da 
Lélia Gonzalez. É importante nessa temática e também fundamental, na perspectiva dela ter sido uma ativista doutora, com formação filosófica, antropológica, e também na área de comunicação, que produziu artigos questionando a história, sociologicamente evidenciando o racismo no Brasil e evidenciando qual era o papel da mulher negra neste trajeto histórico (MALACHIAS, 2018).

No Instituto de Filosofia e Ciências Sociais da UFRJ, o laboratório de Pesquisa em Filosofia Africana, coordenado por Ribeiro, oferece disciplinas na mesma linha, o que representa um "grande avanço e mostra uma abertura significativa para repensar as questões raciais e os pensamentos heterodoxos no campo da Filosofia" (RIBEIRO, 2018).

Os entrevistados apontam avanços ainda tímidos, seja pelo desconhecimento, seja pela herança do racismo, que não possibilita a abertura. Uma das áreas apontadas como precursora no debate, segundo Cláudia Miranda, é o campo da Educação, “onde mais se desenvolveu a discussão sobre desigualdades raciais. Temos alguns colegas que já trabalham com a perspectiva da interculturalidade, mesmo sem ser chamada dessa forma” (MIRANDA, 2018).

Nesse conjunto de preocupações, alguns colegas inserem a questão de uma outra literatura, a partir de textos, referências fílmicas ou reconhecimento das experiências de diferentes lideranças. Mas, destaco, que esta é a prática de alguns colegas. A grande maioria ainda não lida, não sabe, não conhece e pouco dialoga com este universo de questões. Infelizmente, isto não é uma preocupação do corpo docente (MIRANDA, 2018).

Há exceções e boas perspectivas. Para Malachias, o fato de a unidade onde trabalha estar localizada em Duque de Caxias, um município da Baixada Fluminense, e contar com um quadro grande de docentes negros, faz com que a discussão sobre raça seja um assunto caro a todos. “Tenho observado, e posso falar do lugar do Departamento de Ciência e Fundamentos da Educação, que as questões de referências bibliográficas têm sido pontuadas nas reuniões de docente e buscam uma certa coerência com a mudança curricular que nos foi exigida" (MALACHIAS, 2018). A entrevistada defende que tanto a Faculdade de Educação da Baixada Fluminense como outras faculdades de Educação precisam implementar uma reforma curricular no âmbito da Pedagogia.

É possível, então, que autores que antes não constavam nas referências passem a constar nos novos cursos, como o de relações étnico-raciais, 
direitos humanos, enfim. Não vejo uma resistência grande de pontuar a necessidade de novas referências, que talvez não sejam tão novas, mas sejam desconhecidas na perspectiva eurocêntrica das universidades. (MALACHIAS, 2018).

Fernanda Felisberto também celebra o fato de atuar ao lado de dez professores negros e, por causa disso, construir um novo caminho no ensino e diálogos de autocuidado com os alunos, mas ressalta que esta abertura aparece de maneira consolidada justamente fora da "grande rota de produção de conhecimento, estamos à margem, na Baixada Fluminense" (FELISBERTO, 2018).

A preocupação acima se materializa diante da constatação da professora Claudia Miranda de que "a Unirio avançou pouquíssimo em termos, por exemplo, de criar um núcleo de estudos afro-brasileiros" (MIRANDA, 2018). Nemézio Amaral Filho reitera que no Departamento de Comunicação, onde leciona, a "política racial não é debatida até o momento. As discussões são apenas pontuais” (AMARAL FILHO, 2018). Para Luciene Dias, apenas o fato de existir dentro de uma universidade é uma forma de contribuição. No entanto, "no momento em que estamos, não pensarmos no racismo é impossível, seria bom podemos acordar um dia sem termos que lidar com o fato de sermos negros" (DIAS, 2018).

\section{Comunicação espelha um país branco diante de maioria negra}

A ausência da diversidade racial na mídia, a presença ostensiva de pessoas brancas e a invisibilidade naturalizada do negro nas produções midiáticas e culturais são alguns dos problemas centrais do sistema midiático brasileiro. Sodré (2015) compreende a mídia como o intelectual coletivo de elites inclinadas ao capital financeiro e desvinculadas dos "ganhos democráticos [...] e (que) abrem mão de políticas nacionalmente soberanas.” (SODRÉ, 2015, p. 244). Nesse contexto, a mídia não se compromete com a diversidade da população brasileira. Também produz pequenas elites - definidas por Sodré como elites logotécnicas formadas por editorialistas, articulistas, editores, colunistas, âncoras de televisão, jornalistas especiais, etc. principais zeladoras da reprodução e disseminação do imaginário coletivo.

A presença ostensiva de pessoas brancas na ocupação destes cargos e nos produtos e discursos emitidos cotidianamente pela mídia é elemento revelador de circunstâncias e fatores que operam na sociedade e dão sustentabilidade a este cenário. Foi somente em pleno século 
XXI (agosto de 2018) e, portanto, em mais de cinquenta anos de história da televisão brasileira, que dois apresentadores negros, a jornalista Luciana Camargo e o colega Rodrigo Cabral, dividiram a bancada de um telejornal. Segundo os próprios jornalistas, a junção foi aleatória, resultante da escala de trabalho. No entanto, o fato expõe a ausência de âncoras negros no comando de telejornais brasileiros, que mantém majoritariamente duplas brancas e, raramente, um/a âncora negro/a fazendo dupla com um/a âncora branco/a. Essa falta é a principal crítica de Dias:

\begin{abstract}
Representatividade: esta é a única forma de alterarmos esse movimento imposto pela mídia massificada. Enquanto os espaços de comunicação não forem diversificados, outras vozes não serão ouvidas e, se forem, será de um modo artificial. Precisamos de bancadas de telejornais com âncoras negros, de jornalistas, em geral, negros, de docentes negros nas universidades etc. (...) Se o ponto de vista de um negro não é escutado quando, por exemplo, as pautas de um telejornal são pensadas, no produto final ele não existirá (DIAS, 2018).
\end{abstract}

Ainda que o estudo da representação social na mídia seja um campo em expansão, não se pode negar o papel central que os meios de comunicação de massa desempenham na disseminação da representação do lugar do negro no imaginário social. Sodré chama a atenção para o imaginário racista como uma categoria analítica fundamental na leitura das representações preconceituosas sobre o negro.

0 imaginário racista veiculado pelas elites tradicionais pode ser hoje reproduzido logotecnicamente, de modo mais sutil e eficaz, pelo discurso mediático-popularesco, sem distância crítica do tecido da civilização tecnoeconômica, onde se acha incrustada a discriminação em todos os níveis" (SODRÉ, 2015, p. 245).

Ao alimentar o tecido social de leituras e imagens estereotipadas sobre a pessoa negra, a mídia desempenha um papel chave na manutenção das hierarquias sociais. 0 conceito de midiatização - ou o espraiamento da mídia nas instituições sociais até tornar-se onipresente na vida social dos cidadãos e das instituições - tonifica a força política da mídia na influência no tecido social. Um dos fatores que tem dado sustentabilidade a esta força política da mídia é a estrutura racista e excludente na qual se situa a sociedade brasileira. 
Os meios de comunicação estão trabalhando a favor de um projeto de país que não favorece as populações, mas, sim, as famílias que sempre tiveram o poder de decidir e ocupar as diferentes instâncias da nossa sociedade. Essa comunicação trabalha em função de manutenção das hierarquias e da fixação das populações negras, já que para a chamada grande mídia o racismo permanecer é fundamental para que essas elites, que governam e que decidem, se mantenham (MIRANDA, 2018).

As produções das novelas brasileiras são exemplos frequentes da invisibilidade da pessoa negra e da naturalização das hierarquias em que o negro ocupa um papel de subalternidade e estereotipado. Um debate acalorado que envolveu internautas nas redes sociais em 2018 foi sobre a ausência de atores negros na novela "Segundo Sol", da TV Globo, ambientada em Salvador, identificada como a capital com o maior número de pessoas negras no país. Após as denúncias e ameaças de protestos, a emissora trouxe a presença negra de forma sutil, com uma participação em algumas cenas de figurantes negros. Mais recentemente, uma atriz negra ocupou o papel de advogada da protagonista da novela, contudo, sem construir vínculo familiar.

O núcleo central da novela, por sua vez, mantém uma mulher negra no papel de empregada doméstica, que gerou dois filhos do patrão branco, um branco e um negro. Tal configuração familiar dialoga com o que Liv Sovik, na obra Aqui ninguém é branco, classifica como a necessidade de novas formas de analisar as hierarquias raciais, cujas práticas permanecem sem a suposta justificação da origem biológica, citando precisamente o caso de um mesmo casal ter filhos que podem ser classificados como negros e brancos, sem que isso abale a hierarquização racial (SOVIK, 2009, p.17). A ausência de fundamentação científica para a suposta inferiorização da população negra não interrompe os processos racistas, seja no interior da família de origem, seja nas relações cotidianas. As novas formas de analisar as hierarquias raciais devem observar a capacidade que uma afirmação tem para atrair a adesão de determinado público em relação à falsidade da inferioridade de negros e indígenas.

A trama da novela reforça o estigma e o preconceito. 0 filho com o tom de pele clara foi criado pela família rica e o de pele escura pela mãe, ambos na mesma casa. Os privilégios na educação e formação foram inevitáveis. Sugere-se uma associação com o imaginário da casa grande e as relações estabelecidas com os/as escravizados/as que lá habitavam. A empregada doméstica, por vezes, apropria-se do lugar de autoridade da dona da casa, que nos remete à personagem Chica da Silva, ex-escravizada que teve papel relevante na história brasileira, 
porém é estereotipada no imaginário social. Na trama da TV Globo, o filho da empregada de pele escura revela que sua fortuna é oriunda do tráfico de diamantes africanos, ou seja, o personagem corresponde ao estereótipo do negro fora-da-lei. A novela Segundo Sol naturalizou a relação entre o patrão branco e a empregada doméstica negra e manteve as hierarquias sociais, nas quais a pessoa negra aparece constantemente subalternizada.

Malachias identifica o processo de manutenção das hierarquias sociais ao longo da História - seja por meio das produções culturais seja por meio das produções jornalísticas:

\begin{abstract}
Se pensarmos a comunicação, estamos num período que é fundamental a releitura daquilo que seria visto como ideal. Quando esse ideal nos é apresentado pela grande mídia - e se fizermos uma leitura crítica sobre isso - temos condições de perceber nitidamente que o processo colonial permanece, que a imposição eurocêntrica permanece, a exclusão da população negra na TV permanece, a imposição de uma branquitude permanece, e por essa razão, é fundamental criarmos nossas próprias mídias (MALACHIAS, 2018).
\end{abstract}

Sodré diz que a indústria cultural empreende o racismo no sentido dado por Mauss para a palavra instituição, ou seja, no "modo de fazer ou de pensar independente do indivíduo" (SODRÉ, 2015, p. 245). Parece-nos que Sodré já nomeava no Brasil o que fora classificado como racismo institucional pelo movimento Black Power nos Estados Unidos. Na mídia, este racismo emerge por meio de fatores identificados como a negação, o recalcamento, a estigmatização e a indiferença profissional.

A negação define-se pela tendência da mídia de negar a existência do racismo, dedicando-se a coberturas artificiais de episódios e/ou conflitos raciais. Já o recalcamento remete a uma espécie de silenciamento da mídia sobre o papel do negro na produção cultural brasileira. Este tipo de racismo gera, na mídia, profissionais ignorantes sobre a história do negro no Brasil ou na diáspora. A estigmatização e a indiferença profissional são, respectivamente: 1) a capacidade de desqualificar a diferença e reproduzi-la como marca da inferioridade; e 2) o foco prioritário da mídia contemporânea no lucro e na publicidade que minimiza a discriminação contra a pessoa negra e os problemas que afetam esta população em decorrência do racismo. Estes assuntos não despertam o interesse midiático. 
0 racismo e suas dinâmicas nas práticas midiáticas estão inseridos na leitura mais ampla de Sodré sobre a mídia e a comunicação no contexto da Modernidade. Interessa-nos destacar, nas reflexões desenvolvidas por este autor, o problema epistemológico do campo científico da comunicação e a "ambiguidade institucional de suas condições de possibilidade" (SODRÉ, 2012, p.15). Assim como nas escolas de economia - onde não é ensinada a ciência econômica, mas os métodos aplicáveis à administração dos fluxos do mercado, nas escolas de comunicação - submersas num mundo globalizado e inseridas na imbricação entre o capitalismo financeiro e a comunicação - se reproduzem o que Sodré chama de "ideologia privatista, que elege como maiores valores sociais a eficácia produtiva e o sucesso pessoal." (Idem, ibidem, p. 16).

Estas dinâmicas estão inseridas nas percepções de Felisberto e Amaral Filho. A primeira ressalta a falsa ideia do racismo velado e o recente recrudescimento do mesmo, com o apoio da mídia, diante de um movimento negro desprovido de capacidade de reação na mesma velocidade da reconfiguração do racismo.

\begin{abstract}
A história real dos negros brasileiros, que é uma experiência diferente do ser africano ou branco, eu acho que vai acontecer a partir da historiografia, da comunicação dos que foram silenciados [...], construindo novas formas, abordando novas autorias para nos representar [...]. Era uma grande mentira que o racismo era velado, agora a gente está diante de um racismo frontal. A gente não conseguiu se armar na mesma velocidade que o racismo se refez, se reconfigurou. Frontalmente e declarado, a mídia está fazendo o que tem vontade e agora precisamos correr para construir mais ferramentas (FELISBERTO, 2018).
\end{abstract}

Amaral Filho, por sua vez, preocupa-se com o cenário de retrocesso político brasileiro instalado desde 2016, o esvaziamento do debate público e o impacto destas perdas para a população negra.

0 momento de inflexão política que estamos vivendo tem afetado negativamente o debate que vinha ganhando corpo na sociedade acerca das relações raciais. De repente, o mais importante é a luta para retomada plena da democracia; luta que, como nos anos de chumbo, fez com que as demais pautas sociais fossem tragadas pela espiral do silêncio. Mesmo entre as esquerdas, nota-se uma priorização de questões macro - de certa maneira, uma atitude compreensível - num caminho que esvazia lutas mais pontuais como das mulheres, negros e grupos LGBTs (AMARAL FILHO, 2018). 
Para o pesquisador, o retrocesso a que fomos submetidos desde o golpe de 2016, com a ruptura democrático-institucional, ainda não foi mensurado.

É nesse contexto a necessidade de tornar visível a questão racial, com seu imperativo de garantir a manutenção dos direitos obtidos e de avançar nas conquistas sociais. É preciso pensar novas estratégias [...]. Precisamos aprender a fazer a nova política no sentido de que não é possível dizer as mesmas coisas para as mesmas pessoas do mesmo jeito o tempo todo. Temos que conseguir mais e novos aliados e aprender a usar as mídias de maneira mais inteligente do que temos feito até agora (AMARAL FILHO, 2018).

Dentre as observações críticas sobre o quadro midiático, destacamos a reprodução dos estereótipos sobre a população negra, a função da elite midiática na manutenção das hierarquias raciais no imaginário coletivo e também a capacidade da indústria cultural de reproduzir o chamado racismo institucional. Tais fatores resultam na ausência da diversidade racial na mídia e na naturalização da maneira que a presença do negro é retratada nas produções midiáticas. Consideramos que a negação do racismo e o silêncio midiático sobre o papel do negro na cultura brasileira - reforçados pela estigmatização e pela indiferença profissionais -, estão inseridos no que Sodré classificou como problema epistemológico do campo científico da comunicação. Os efeitos da imbricação entre o capitalismo financeiro e o campo da comunicação fortalecem, desde a formação profissional, valores sociais que sustentam a ideologia capitalista.

\section{Considerações finais}

Este artigo é parte de um exercício colaborativo de leitura, debate, reflexão e escrita, realizado pelo Grupo de Estudos sobre Relações Raciais no Brasil. 0 estudo aqui apresentado não se propôs a ser uma ampla investigação, porém, por se tratar de uma primeira experiência do grupo, pode ter desdobramentos futuros. Inicialmente foram indicados 12 intelectuais negros, professores e professoras com doutorado ou pós-doutorado, dentre os quais sete representantes do gênero feminino e cinco representantes do masculino. Deste total, quatro eram do campo da comunicação. A ideia foi trazer o olhar de intelectuais de diferentes áreas do conhecimento para abordar a temática do racismo e suas implicações. Ainda em referência ao 
total, sete, seis mulheres e um homem, participaram efetivamente, dando entrevistas. Os demais indicados ou não foram encontrados ou não responderam ao convite.

Os resultados obtidos, até aqui, demonstram que as/os intelectuais negras e negros inseridos na academia têm reflexões relevantes sobre o campo da comunicação, o paradigma branco que domina a mídia brasileira, e seus impactos socioculturais na academia e na sociedade em geral. 0 combate ao racismo é central nas abordagens dos/as entrevistados, na mídia e na academia. Constatamos como o racismo ainda é presente na sociedade e também no meio acadêmico. Demonstramos avanços importantes, como a abertura para o debate no campo da educação e a combatividade real e simbólica a partir da presença de acadêmicos negros e negras em instituições de ensino superior. Existir na universidade, neste contexto, se torna um ato político, segundo os entrevistados, que ressaltam, ainda, a necessidade de defender e ir além das leis que garantem o acesso às universidades. Dentre as ações destacadas pelos intelectuais como fundamentais para tornar estes espaços, de fato, mais plurais estão: bibliografias não eurocêntricas, debates constantes sobre relações raciais e, fundamentalmente, o combate efetivo a todo e qualquer ato racista que ocorra no âmbito universitário.

Apesar do tom, em sua maioria, otimista sobre as mudanças que vêm ocorrendo nos últimos anos, através da maior inclusão de docentes e discentes negros, se evidencia uma preocupação no discurso dos entrevistados sobre como ainda há uma sensação de solidão em suas lutas. A ínfima presença de professores negros/as nas salas de aula e nos corredores universitários e a ausência de políticas institucionais que tratem de questões raciais acentuam esse sentimento, afirmam. Porém, ganham força iniciativas que partem dos próprios professores negros/as, atuante nas faculdades, em busca de suprir as brechas deixadas pelas instituições, através da criação de núcleos, laboratórios, grupos de estudo, coletivos, dentre outras.

Por fim, o discurso ressonante entre os intelectuais entrevistados é de transformação em curso, embora reconheçam que ainda há muito a ser feito para garantir, na universidade, a representatividade de todas as minorias sociais. A segregação ainda é uma realidade, mas há um esforço, especialmente por parte dos profissionais negros/as, a fim de fazer emergir a "existência e aprofundamento de todos os particulares", como Aimé Césaire desejou em carta 
enviada ao político Maurice Thorez, do Partido Comunista francês, em 24 de outubro de 1956, criticando o debate e a luta exclusivamente classistas.

\section{Referências bibliográficas}

ALMEIDA, Silvio. O que é racismo estrutural. 2018. Belo Horizonte. Ed. Letramento, Justificando, 2018.

CARNEIRO, Sueli. Enegrecer o feminismo: a situação da mulher negra na América Latina a partir de uma perspectiva de gênero, In: Ashoka Empreendedores Sociais (org.). São Paulo: Editora Takano, 2003, p. 49-58.

CÉSAIRE, Aimé. Discurso sobre a Negritude. MOORE, Carlos (Org.). Belo Horizonte: Nandyala, 2010.

. Discurso sobre o Colonialismo. Lisboa: Livraria Sá da Costa Editora, 1985.

DERRIDA, Jacques. A universidade sem condição. São Paulo: Estação Liberdade, 2003.

FANON, Frantz. Pele negra, máscaras brancas. Salvador: EDUFBA, 2008.

HALL, Stuart. Da Diáspora: identidades e mediações culturais. Belo Horizonte: Ed. UFMG, 2003. Nao identifiquei citação desse livro no texto.

. "Quem precisa da identidade". In: Tomas Tadeu da Silva (org.). Identidade e diferença: a perspectiva dos Estudos Culturais. Petrópolis: Ed. Vozes, 2000.

MBEMBE, Achille. Crítica da Razão Negra. Lisboa: Ed. Antígona, 2017.

MOORE, Carlos. Prefácio "Negro Sou, Negro Ficarei" - A negritude segundo Aimé Césaire. In: CÉSAIRE, Aimé. Discurso sobre a Negritude. MOORE, Carlos. (Org,). Belo Horizonte: Nandyala, 2010.

MUNANGA, Kabengele. Negritude: usos e sentidos. 2. Ed. São Paulo: Ática, 1988.

. Rediscutindo a mestiçagem no Brasil: Identidade nacional versus identidade negra. Petrópolis: Vozes, 2001.

RIBEIRO, Djamila. O que é lugar de fala? Belo Horizonte: Letramento, Justificando, 2017.

SILVA, Tadeu Tomaz da. Identidade e Diferença. Petrópolis: Vozes, 2000.

SODRÉ, Muniz. Claros e escuros: identidade, povo e mídia no Brasil. Petrópolis, RJ: Vozes, 2015. $3^{\mathrm{a}}$. Ed. . Reinventando a educação. Petrópolis, RJ: Ed. Vozes, 2012. 
SOVIK, Liv. Aqui ninguém é branco. Rio de Janeiro: Aeroplano, 2009.

\section{Entrevistas}

AMARAL FILHO, Nemézio. Professor da Faculdade de Comunicação Social da Universidade do Estado do Rio de Janeiro (UERJ). Entrevista concedida em agosto de 2018.

DIAS, Luciene. Professora da Faculdade de Informação e Comunicação da Universidade Federal de Goiás (UFG). Entrevista concedida em agosto de 2018.

FELISBERTO, Fernanda. Professora do Departamento de Letras da Universidade Federal Rural do Rio de Janeiro (UFRRJ). Entrevista concedida em agosto de 2018.

MALACHIAS, Rosangela. Professora da Faculdade de Educação da Baixada Fluminense da Universidade do Estado do Rio de Janeiro (UERJ). Entrevista concedida em agosto de 2018.

MIRANDA, Claudia. Professora da Escola de Educação da Universidade Federal do Estado do Rio de Janeiro (Unirio). Entrevista concedida em agosto de 2018.

REZENDE, Maria Alice. Professora do Departamento de Ciências Sociais e Educação da Universidade do Estado do Rio de Janeiro (UERJ). Entrevista concedida em agosto de 2018.

RIBEIR0, Katiúscia. Professora do Instituto de Filosofia e Ciências Sociais (IFCS) da Universidade Federal do Rio de Janeiro (UFRJ). Entrevista concedida em agosto de 2018. 